\title{
Synthesis, Crystal Structure of Mg(II) Complex Material and its Application as Catalysts for $\mathbf{A}^{3}$ Coupling Reaction
}

\author{
Xi-Shi Tai ${ }^{*}$ and Li-Li Liu
}

\author{
College of Chemistry and Chemical Engineering, Weifang University, Weifang 261061, China
}

\begin{abstract}
The ligand of 1, 2-phenylenedioxydiacetic acid $\left(\mathrm{H}_{2} \mathrm{~L}\right)$ has been employed to react with $\mathrm{MgCl}_{2} \cdot 6 \mathrm{H}_{2} \mathrm{O}$ in water/ethanol solution (v:v $=1: 1$ ), to yield a novel $\mathrm{Mg}(\mathrm{II})$ complex $\left[\mathrm{MgL}\left(\mathrm{H}_{2} \mathrm{O}\right)_{3}\right] \cdot 3.5 \mathrm{H}_{2} \mathrm{O}$. The complex was characterized by infrared spectroscopy and single crystal X-ray diffraction structural analysis. The results show that the $\mathrm{Mg}$ (II) complex belongs to monoclinic, space group $C_{2} / \mathrm{c}$ with $a=2.9160(6) \mathrm{nm}, b=0.67617(14) \mathrm{nm}, c=1.7319(4) \mathrm{nm}, \beta=109.06(3)^{\circ}, V$ $=3.2275(11) \mathrm{nm}^{3}, Z=8, D_{c}=1.562 \mu \mathrm{g} \cdot \mathrm{m}^{-3}, \mu=0.184 \mathrm{~mm}^{-1}, F(000)=1560$, and final $R_{1}=0.0703, \omega R_{2}=0.2256$. The complex molecules form a $3 \mathrm{D}$ network structure through hydrogen bonds and $\pi-\pi$ stack. The $\mathrm{A}^{3}$ coupling reaction of phenylacetylene, aldehyde and amine (piperidine) in the presence of $\mathrm{Au} @ \mathrm{Mg}(\mathrm{II})$ complex as an efficient heterogeneous catalyst has been studied.
\end{abstract}

Keywords: 1,2-phenylenedioxydiacetic acid, catalytic property, crystal structure, $\mathrm{Mg}(\mathrm{II})$ complex, synthesis.

\section{INTRODUCTION}

Metal complex materials have been to attract the interest of chemists for many years, which may bring both intriguing architectures and promising potential applications in fields such as catalysis, gas storage, magnetics, luminescence materials, and so on [1-7]. In particular, aromatic carboxylic acid ligands play an important role in the construction of metal complex materials by their multiform coordination ways [8-12]. Early reports on aromatic carboxylate complexes are mostly focused on the transition metal complexes [13-15]. Magnesium ions take part in many biochemical activities in life. So the studies on the synthesis, structure and properties of $\mathrm{Mg}$ (II) complexes have important significance. With considering the points mentioned above, 1, 2-phenylenedioxydiacetic acid $\left(\mathrm{H}_{2} \mathrm{~L}\right)$ was chosen as the organic ligand to construct new $\mathrm{Mg}$ (II) complex materials. We report here the synthesis, crystal structure and catalytic property of a novel $\mathrm{Mg}$ (II) complex (Scheme 1).

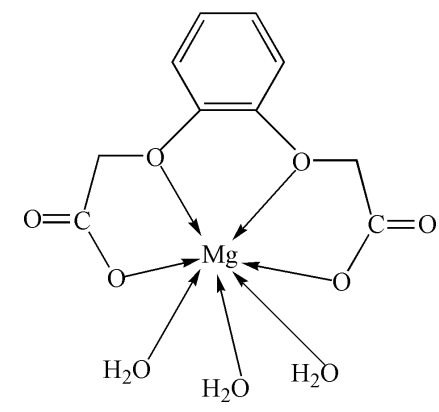

Scheme 1. The coordination mode $\mathrm{Mg}(\mathrm{II})$ ion.

*Address correspondence to this author at the College of Chemistry and Chemical Engineering, Weifang University, Weifang 261061, China;

E-mails: taixishi@Lzu.edu.cn, taixs@wfu.edu.cn

\section{EXPERIMENTAL SECTION}

\section{Materials and Methods}

The 1,2-phenylenedioxydiacetic acid ligand, $\mathrm{MgCl}_{2} \cdot 6 \mathrm{H}_{2} \mathrm{O}$, $\mathrm{HAuCl}_{4} \cdot 4 \mathrm{H}_{2} \mathrm{O}$, 2,2-bipyridine, 1,4-dioxane, benzaldehyde, phenylacetylene, and piperidine were commercial materials of analytical grade.

$\mathrm{C}, \mathrm{H}$ and $\mathrm{N}$ were carried out on Elementar Vario EL III elemental analyzer. The FT-IR spectra were obtained on a Nicolet AVATAR 360 FTIR spectrometer with $\mathrm{KBr}$ pellets in the range of $4,000 \mathrm{~cm}^{-1} \sim 400 \mathrm{~cm}^{-1}$. The catalytic products were quantified by GC analysis (GC-1100 equipped with a $0.25 \mathrm{~mm} \times 0.25 \mathrm{~mm} \times 30 \mathrm{~m} \mathrm{SE}-54$ capillary column). The single crystal diffraction data of the $\mathrm{Mg}(\mathrm{II})$ complex was collected on a Bruker smart CCD diffractometer.

\section{Synthesis of Mg(II) Complex}

Amounts of $0.5 \mathrm{~m} \mathrm{~mol}(0.1131 \mathrm{~g})$ of $\mathrm{H}_{2} \mathrm{~L}, 1.0 \mathrm{~m} \mathrm{~mol}$ $(0.040 \mathrm{~g})$ of $\mathrm{NaOH}$ and $0.5 \mathrm{~m} \mathrm{~mol}(0.1015 \mathrm{~g})$ of $\mathrm{MgCl}_{2} \cdot 6 \mathrm{H}_{2} \mathrm{O}$ were dissolved in $10 \mathrm{~mL}$ of $\mathrm{CH}_{3} \mathrm{CH}_{2} \mathrm{OH} / \mathrm{H}_{2} \mathrm{O}$ $(\mathrm{v}: \mathrm{v}=1: 1)$ solution. The mixture was reacted for $1.5 \mathrm{~h}$ at room temperature, then $0.5 \mathrm{mmol}(0.0782 \mathrm{~g})$ 2,2-bpy solid was added to the solution and the mixture was further heated for $3 \mathrm{~h}$ at refluxing temperature. The reaction mixture was filtrated. The crystals were obtained by evaporating methanol solution of $\mathrm{Mg}(\mathrm{II})$ complex. Elementary analysis: calcd for $\mathrm{C}_{10} \mathrm{H}_{21} \mathrm{MgO}_{12.5}$ : C, 32.88; H, 5.75; found: C, 33.16; $\mathrm{H}, 5.38$. IR $v_{\max }\left(\mathrm{cm}^{-1}\right): v(\mathrm{O}-\mathrm{H}): 3,250 \mathrm{~cm}^{-1}, v_{\text {as }}\left(\mathrm{COO}^{-}\right): 1,638$ $\mathrm{cm}^{-1}, v_{\mathrm{s}}\left(\mathrm{COO}^{-}\right): 1,442 \mathrm{~cm}^{-1}, v(\mathrm{C}-\mathrm{O}-\mathrm{C}): 1,220 \mathrm{~cm}^{-1}, v(\mathrm{Mg}-$ O):421 $\mathrm{cm}^{-1}$.

\section{X-Ray Crystallography}

Suitable single crystals with approximate dimensions of $0.38 \mathrm{~mm} \times 0.32 \mathrm{~mm} \times 0.28 \mathrm{~mm}$ was mounted on a glass 
fiber and used for X-ray diffraction analyses. Data were collected on a Bruker smart CCD diffractometer at 273(2) K using a graphite-monochromatic Mo $K \alpha$ radiation $(\lambda=$ $0.71073 \AA$ ). The structure was solved by direct methods with SHELXL-97 [16]. The molecular graphics were drawn with the SHELXTL-97 program package [17]. The data collection and handling for the $\mathrm{Mg}(\mathrm{II})$ complex structure are listed in Table 1. Important bond lengths and angles have been shown in Table 2.

Table 1. The data collection and handling details for $\mathrm{Mg}$ (II) complex.

\begin{tabular}{|l|l|}
\hline Formula & $\mathrm{C}_{10} \mathrm{H}_{11} \mathrm{MgO}_{14}$ \\
\hline Formula weight & 379.50 \\
\hline Crystal system & Monoclinic \\
\hline Space group & $C_{2} / \mathrm{c}$ \\
\hline$a / \mathrm{nm}$ & $2.9160(6)$ \\
\hline$b / \mathrm{nm}$ & $0.67617(14)$ \\
\hline$c / \mathrm{nm}$ & $1.7319(4)$ \\
\hline$\beta\left({ }^{\circ}\right)$ & $109.06(3)$ \\
\hline$Z$ & 8 \\
\hline$F(000)$ & 1560 \\
\hline Temperature $(\mathrm{K})$ & $293(2)$ \\
\hline$V / \mathrm{nm}^{3}$ & $3.2275(11)$ \\
\hline Calculated density $\left(\mu \mathrm{g} \cdot \mathrm{m}^{-3}\right)$ & 1.562 \\
\hline Crystal size $\left(\mathrm{mm}{ }^{3}\right)$ & $0.38 \times 0.32 \times 0.28$ \\
\hline Limiting indices & $-38 \leq h \leq 28$, \\
& $-8 \leq k \leq 8$, \\
& $-22 \leq l \leq 22$ \\
\hline Reflections collected/unique & $9920 / 3142$ \\
\hline Data/restraints/parameters & $3887 / 0 / 226$ \\
\hline$R_{\text {int }}$ & 0.0199 \\
\hline$R_{1}, w R_{2}($ all data $)$ & $0.0818,0.2361$ \\
\hline$R_{1}, w R_{2}(I>2 \sigma(I))$ & $0.0703,0.2256$ \\
\hline Largest diff.peak and hole $\left(\mathrm{e} \cdot \mathrm{nm}{ }^{-3}\right)$ & $849,-1192$ \\
\hline & \\
\hline
\end{tabular}

\section{Preparation of Au@Mg(II) Complex Catalyst (AMCC)}

For synthesis of $\mathrm{Au} @ \mathrm{Mg}(\mathrm{II})$ complex catalyst by impregnation, a solution of $\mathrm{HAuCl}_{4} \cdot 4 \mathrm{H}_{2} \mathrm{O}(0.020 \mathrm{~g})$ in $0.5 \mathrm{ml}$ $\mathrm{MeCN}$ was dropwise added to the $\mathrm{Mg}$ (II) complex support at room temperature and was sonicated for about $0.5 \mathrm{~h}$. Then the sample was aged at room temperature for $12 \mathrm{~h}$ and dried at $50{ }^{\circ} \mathrm{C}$ for $10 \mathrm{~h}$ under air atmosphere. The as-synthesized sample was finally dried overnight at $323 \mathrm{~K}$ under air atmosphere to yield $\mathrm{Au} @ \mathrm{Mg}(\mathrm{II})$ complex catalyst.

\section{Catalytic Measurements}

Typical procedure for the $\mathrm{A}^{3}$ coupling reaction: the mixture of benzaldehyde $(0.25 \mathrm{mmol}, 0.027 \mathrm{~g})$, phenylacetylene $(0.325 \mathrm{mmol}, 0.034 \mathrm{~g})$, piperidine $(0.300$ mmol, $0.026 \mathrm{~g})$, and supported gold catalyst $(0.07 \mathrm{~g})$ were added into $1.500 \mathrm{~g} \mathrm{1,4-dioxane.} \mathrm{The} \mathrm{mixture} \mathrm{was} \mathrm{reacted} \mathrm{at}$ $120{ }^{\circ} \mathrm{C}$ for $11 \mathrm{~h}$. Then the catalysts were removed from the solution. The products were quantified by $\mathrm{GC}$ analysis $(\mathrm{GC}-$ 1100 equipped with a $0.25 \mathrm{~mm} \times 0.25 \mathrm{~mm} \times 30 \mathrm{~m} \mathrm{SE}-54$ capillary column). The GC analysis conditions were as follows: initial column temperature $50^{\circ} \mathrm{C}$, to $280{ }^{\circ} \mathrm{C}$ at 10 ${ }^{\circ} \mathrm{C} / \mathrm{min}$, and hold for $20 \mathrm{~min}$.

Table 2. Selected bond lengths ( $\AA$ ) and angles $\left(^{\circ}\right)$ for $\mathrm{Mg}(\mathrm{II})$ complex.

\begin{tabular}{|c|c|c|c|}
\hline Bonds & Bond Parameter & Bonds & Bond Parameter \\
\hline \hline $\mathrm{Mg} 1-\mathrm{O} 1$ & $0.2431(2)$ & $\mathrm{Mg} 1-\mathrm{O} 7$ & $0.2068(2)$ \\
\hline $\mathrm{Mg} 1-\mathrm{O} 2$ & $0.2117(2)$ & $\mathrm{Mg} 1-\mathrm{O} 8$ & $0.2030(2)$ \\
\hline $\mathrm{Mg} 1-\mathrm{O} 4$ & $0.23966(19)$ & $\mathrm{Mg} 1-\mathrm{O} 9$ & $0.2052(2)$ \\
\hline $\mathrm{Mg} 1-\mathrm{O} 5$ & $0.21416(19)$ & & \\
\hline O1-Mg1-O4 & $62.50(6)$ & O2-Mg1-O5 & $160.89(8)$ \\
\hline O1-Mg1-O5 & $130.97(7)$ & O7-Mg1-O5 & $80.85(7)$ \\
\hline O1-Mg1-O2 & $67.80(7)$ & O9-Mg1-O5 & $86.92(8)$ \\
\hline O7-Mg1-O1 & $148.01(8)$ & O8-Mg1-O5 & $90.03(9)$ \\
\hline O1-Mg1-O9 & $88.44(8)$ & O2-Mg1-O7 & $80.77(8)$ \\
\hline O1-Mg1-O8 & $85.96(9)$ & O2-Mg1-O9 & $90.48(8)$ \\
\hline O4-Mg1-O5 & $68.49(6)$ & O2-Mg1-O8 & $95.63(9)$ \\
\hline O2-Mg1-O4 & $129.94(7)$ & O9-Mg1-O7 & $97.88(9)$ \\
\hline O4-Mg1-O7 & $149.28(8)$ & O7-Mg1-O8 & $91.58(9)$ \\
\hline O4-Mg1-O9 & $82.78(8)$ & O9-Mg1-O8 & $169.47(9)$ \\
\hline O4-Mg1-O8 & $86.72(8)$ & & \\
\hline
\end{tabular}

\section{RESULTS AND DISCUSSION}

\section{IR Spectra}

The conspicuous $\mathrm{COO}^{-}$vibration of free ligand is at $1,718 \mathrm{~cm}^{-1}$ and $1,492 \mathrm{~cm}^{-1}$, respectively. In the $\mathrm{Mg}(\mathrm{II})$ complex, they shift $80 \mathrm{~cm}^{-1}$ and $50 \mathrm{~cm}^{-1}$ towards lower wavenumbers, respectively, the $\mathrm{C}-\mathrm{O}-\mathrm{C}$ vibration is at 1,258 $\mathrm{cm}^{-1}$ in the free ligand, and appears at $1,220 \mathrm{~cm}^{-1}$ in the complex, all this indicating that the oxygen atoms of $\mathrm{COO}^{-}$ and $\mathrm{C}-\mathrm{O}-\mathrm{C}$ coordinate to $\mathrm{Mg}$ (II) ions [18]. The strong peak at $3,250 \mathrm{~cm}^{-1}$ is ascribed to the $\mathrm{O}-\mathrm{H}$ stretching vibrations of the coordinated and uncoordinated water. The $v(\mathrm{Mg}-\mathrm{O})$ vibration band is observed at $421 \mathrm{~cm}^{-1}$. Unfortunately, the 2,2-bpy ligand does not take part in coordination with $\mathrm{Mg}$ (II) ion, which is in accordance with the results of X-ray single crystal diffraction analysis.

\section{Structure Description}

The structural analysis shows that the $\mathrm{Mg}$ (II) complex crystallizes in the monoclinic, space group $C_{2} / \mathrm{c}$. From Fig. (1), we can see that the $\mathrm{Mg}(\mathrm{II})$ cation is coordinated by four oxygen atoms from 1, 2-phenylenedioxydiacetic acid ligand $(\mathrm{Mg} 1-\mathrm{O} 1=2.431(2) \AA ̊, \mathrm{Mg} 1-\mathrm{O} 2=2.1190(15) \AA \AA, \mathrm{Mg} 1-\mathrm{O} 4=$ 2.3923(14) $\AA, \mathrm{Mg} 1-\mathrm{O} 5=2.1460(14) \AA$ ), and three oxygen atoms from coordinated water molecules $(\mathrm{Mg} 1-\mathrm{O} 7=$ $2.068(2) \AA, \mathrm{Mg} 1-\mathrm{O} 8=2.030(2) \AA, \mathrm{Mg} 1-\mathrm{O} 9=2.052(2) \AA)$ in 
a distorted orthorhombic geometry. Also, the distances of $\mathrm{Mg}-\mathrm{O}$ are comparable with that observed in other Mg-based complexes [19-21]. The molecules stack with each other via hydrogen bonds in arrays to form a 2D supramolecular structure (Figs. 2, 3).

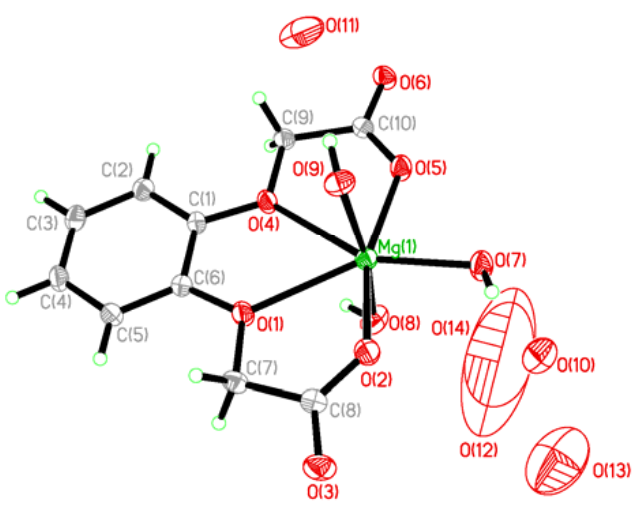

Fig. (1). The molecular structure of the $\mathrm{Mg}(\mathrm{II})$ complex.

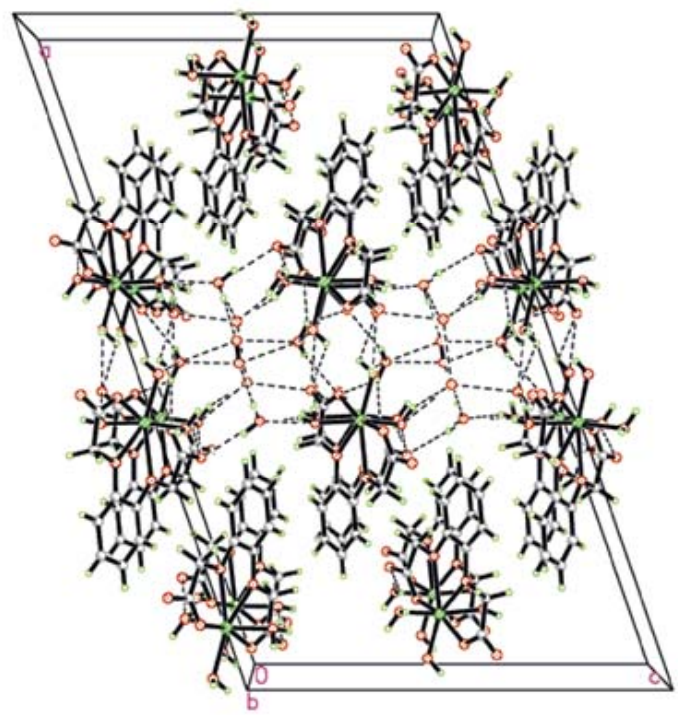

Fig. (2). The molecular packing arrangement of the $\operatorname{Mg}(\mathrm{II})$ complex.

\section{Catalytic Properties}

The catalytic performance of the $\mathrm{Au} @ \mathrm{Mg}(\mathrm{II})$ complex catalyst was assessed in the $\mathrm{A}^{3}$ coupling reaction of benzaldehyde, phenylacetylene, and piperidine. The results are summarized in Table 3. Effect of reaction temperature on the conversion of benzaldehyde over gold functionalized metal-organic frameworks was investigated (Table 3, entries $1,2)$. No higher than $2 \%$ conversion of benzaldehyde was found at the reaction temperature less than $80^{\circ} \mathrm{C}$, and a good

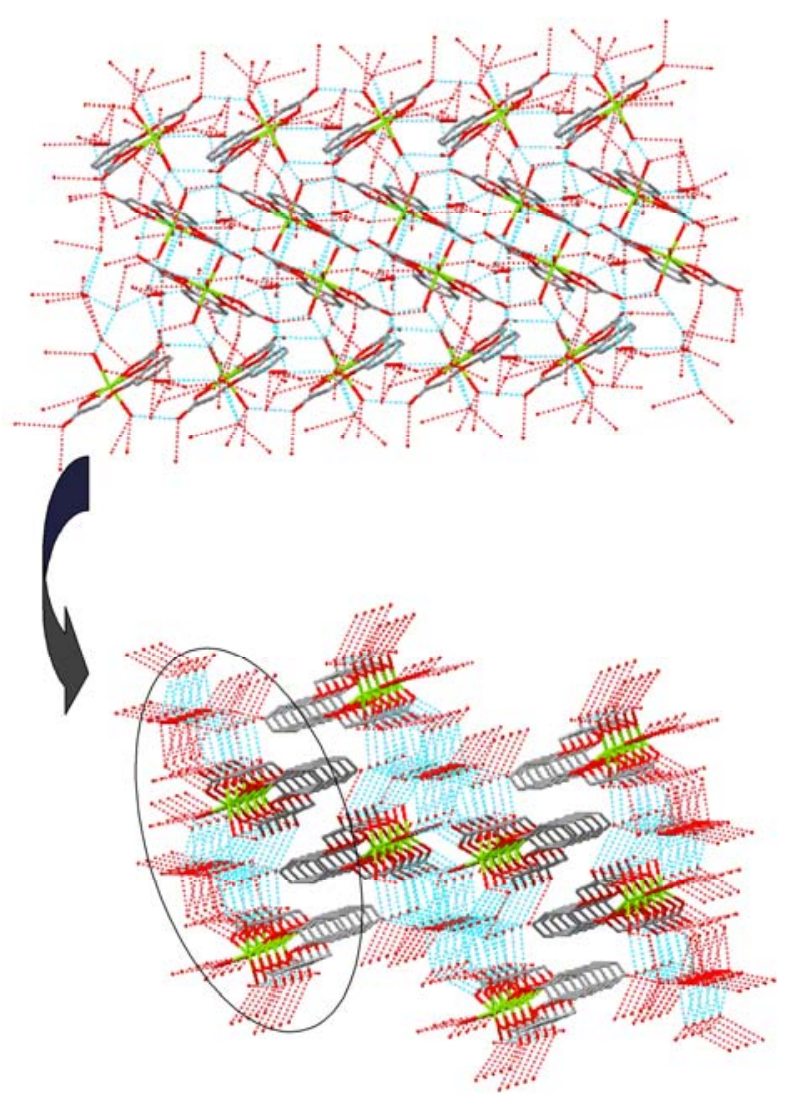

Fig. (3). Infinite 2D networks of $\mathrm{Mg}(\mathrm{II})$ complex.

conversion $(94.1 \%)$ can be obtained at $120^{\circ} \mathrm{C}$. Gold functionalized $\mathrm{Mg}(\mathrm{II})$ complex catalysts feature $100 \%$ selectivity to the product of propargylamine for the $\mathrm{A}^{3}$ coupling reaction.

To examine the scope of the $\mathrm{A}^{3}$ coupling reaction, both aromatic aldehydes and aliphatic aldehydes were coupled with phenylacetylene and piperidine in the presence of $\mathrm{Au} @ \mathrm{Mg}(\mathrm{II})$ complex catalyst. Both aromatic aldehydes and aliphatic aldehydes were able to undergo the corresponding three-component-coupling, and afforded good conversions of aldehydes in the $\mathrm{A}^{3}$ coupling reaction at $120{ }^{\circ} \mathrm{C}$ (Table 3 , entries 2-6). It was found that aromatic aldehydes possessing electron-withdrawing groups (Table 3, entry 4) afforded higher conversions than aryl aldehydes with electrondonating groups bound to the benzene ring (Table 3, entries 3) over $\mathrm{Au} @ \mathrm{Mg}(\mathrm{II})$ complex catalyst. Aliphatic aldehydes such as cyclohexanecarboxaldehyde and n-octaldehyde also display good to excellent conversions with the catalyst Au@Mg(II) complex (Table 3, entries 5, 6).

The reusability studies of $\mathrm{Au} @ \mathrm{Mg}(\mathrm{II})$ complex catalyst were carried out on the $\mathrm{A}^{3}$ coupling reaction of benzaldehyde, phenylacetylene, and piperidine at $120{ }^{\circ} \mathrm{C}$. The results are summarized in Table 4 . The benzaldehyde converision is $94.1 \%$ within $11 \mathrm{~h}$ at $120^{\circ} \mathrm{C}$ over the fresh $\mathrm{Au} @ \mathrm{Mg}(\mathrm{II})$ complex catalyst. After three successive cycles with intermediate extensive washing with 1,4-dioxane, the conversions were $64.1 \%, 48.2 \%$, and $47.6 \%$ at the reaction time of $18 \mathrm{~h}, 24 \mathrm{~h}$, and $26 \mathrm{~h}$, respectively. Clearly, the gold 
Table 3. Coupling of aldehyde, alkyne, and amine catalyzed by $\mathrm{Au} @ \mathrm{Mg}(\mathrm{II})$ complex catalyst complex in dioxane ${ }^{[\mathrm{a}]}$.

$$
\mathrm{R}^{1}-\mathrm{CHO}+\mathrm{R}^{2} \mathrm{R}^{3} \mathrm{NH}+\mathrm{R}^{4} \longrightarrow \mathrm{H} \frac{\text { dioxane } 120^{\circ} \mathrm{C}}{\text { cat. }}
$$

\begin{tabular}{|c|c|c|c|c|c|c|c|}
\hline Entry & Cat. & $\mathbf{R}^{\mathbf{1}}$ & $\mathbf{R}^{\mathbf{2}} \mathbf{R}^{\mathbf{N}} \mathbf{N}$ & $\mathbf{R}^{\mathbf{4}}$ & $\left.\mathbf{T}\left({ }^{\mathbf{0}} \mathbf{C}\right)\right)$ & $\mathbf{T}(\mathbf{h})$ & $\mathbf{C o n v . ( \% )}$ \\
\hline \hline 1 & AMCC & $\mathrm{Ph}$ & piperidine & $\mathrm{Ph}$ & 80 & 12 & 2.0 \\
\hline 2 & AMCC & $\mathrm{Ph}$ & piperidine & $\mathrm{Ph}$ & 120 & 11 & 94.1 \\
\hline 3 & AMCC & $4-\mathrm{MeC}_{6} \mathrm{H}_{4}$ & piperidine & $\mathrm{Ph}$ & 120 & 11 & 16.3 \\
\hline 4 & AMCC & $3-\mathrm{ClC}_{6} \mathrm{H}_{4} 4$ & piperidine & $\mathrm{Ph}$ & 120 & 11 & 75.3 \\
\hline 5 & AMCC & Cyclohexyl & piperidine & $\mathrm{Ph}$ & 120 & 11 & 98.5 \\
\hline 6 & AMCC & Heptyl & piperidine & $\mathrm{Ph}$ & 120 & 11 & 94.1 \\
\hline
\end{tabular}

${ }^{\mathrm{a}]}$ Reaction conditions: aldehyde $(0.250 \mathrm{mmol})$, amine $(0.300 \mathrm{mmol})$, alkyne $(0.325 \mathrm{mmol})$, catalyst $(0.07 \mathrm{~g})$; ${ }^{[\mathrm{b}]}$ the reaction time was not optimization.

functionalized $\mathrm{Mg}(\mathrm{II})$ complex catalyst features a significant deactivation by around $30 \%$ for the first run, while further recycling leads to $15.9 \%$ and $0.6 \%$ deactivation.

Table 4. Recyclability of $\mathrm{Au} @ \mathbf{M g}$ (II) complex catalyst in $\mathbf{A}^{3}$ coupling reaction of benzaldehyde, piperidine, and phenylacetylene ${ }^{[a]}$.

\begin{tabular}{|c|c|c|c|c|}
\hline Run & Cat. & Time (h) & Conv. (\%) & Selectivity (\%) \\
\hline \hline Fresh & AMCC & 11 & 93.1 & 100 \\
\hline 1 & AMCC & 18 & 64.1 & 100 \\
\hline 2 & AMCC & 24 & 48.2 & 100 \\
\hline 3 & AMCC & 26 & 47.6 & 100 \\
\hline
\end{tabular}

${ }^{[\mathrm{a}]}$ Reaction conditions: benzaldehyde $(0.250 \mathrm{mmol})$, piperidine $(0.300 \mathrm{mmol})$, phenylacetylene $(0.325 \mathrm{mmol})$, and dioxane $(1.5 \mathrm{~g})$, catalyst $(0.07 \mathrm{~g}), 120^{\circ} \mathrm{C}$.

\section{CONCLUSION}

In summary, a $\mathrm{Mg}$ (II) complex material was prepared and characterized. In complex the two chains of carboxylate ligands exhibit different coordination modes. The molecules form two dimensional structures by the hydrogen bonds and $\pi-\pi$ stack. In addition, the catalytic properties reveal that the $\mathrm{Au} @ \mathrm{Mg}(\mathrm{II})$ complex catalyst exhibits good conversion and selectivity for the $\mathrm{A}^{3}$ coupling reaction.

\section{CONFLICT OF INTEREST}

The authors confirm that this article content has no conflict of interest.

\section{ACKNOWLEDGEMENTS}

The authors would like to thank the National Natural Science Foundation of China (No. 21171132 and 20671073), the Project of Shandong Province Higher Educational Science and Technology Program (J14LC01) and Science Foundation of Weifang.

\section{SUPPLEMENTARY MATERIAL}

Crystallographic data for the structure reported in this paper has been deposited with the Cambridge Crystallographic Data Centre as supplementary publication No. CCDC 991526. Copy of the data can be obtained free of charge on application to CCDC, 12 Union Road, Cambridge CB2 1EZ, UK (Fax: +44-1223-336-033; E-mail: deposit@ccdc.cam.ac.uk).

\section{REFERENCES}

[1] Zhou XJ, Li BY, Li GH, et al. Synthesis, structures and luminescent properties of cadmium (II) metal organic frameworks based on 3-pyrid-4-ylbenzoic acid, 4-pyrid-4-ylbenzoicLigands. Cryst Eng Commun 2012; 14: 4664-9

[2] $\mathrm{Xu} \mathrm{WJ}$, Xie ZJ, Zhang LY, et al. Synthesis, structures, characterization and antimicrobial activity of two novel coordination complexes derived from 2-naphthoxyacetic acid. J Iran Chem Soc doi: 10.1007/s13738-013-0401-7.

[3] Tai XS, Yin J, Feng YM, et al. Synthesis and crystal structure of $\mathrm{Ca}$ (II) complex with salicylaldehyde-4-aminobenzene sulfonic acid. Chin J Inorg Chem 2007; 23: 1812-4.

[4] Aurore T, Lydia KB, Dominique M. Coordination versatility and amide shift in mononuclear $\mathrm{Fe}^{\mathrm{II}}$ complexes with the asymmetrical tripod [(6-bromo-2-pyridyl)methyl][(6-pivaloylamido-2-pyridyl)methyl](2-pyridylmethyl)amine (BrMPPA). Eur J Inorg Chem 2013; 2013: 1118-22.

[5] Mobec B, Zubieta J. Syntheses and a solid state structure of a dinuclear molybdenum(V) complex with pyridine. Materials 2010; 3: $150-7$

[6] Tai XS, Zhao WH. Synthesis, structural characterization, and antitumor activity of a $\mathrm{Ca}$ (II) coordination polymer based on 1,6naphthalenedisulfonate and 4,4'-bipyridyl. Materials 2013; 6: 3547 55.

[7] Li Q, Wang Y, Yan PF, Hou GF, Li GM. Two 7,7,8,8tetracyanoquinodimethane lead and zinc complexes featuring 3D and 0D structure: Synthesis, structure and electrochemical properties. Inorganica Chimica Acta 2014; 413: 32-7.

[8] Lu WG, Jiang L, Feng XL, et al. Three 3D coordination polymers constructed by $\mathrm{Cd}(\mathrm{II})$ and $\mathrm{Zn}(\mathrm{II})$ with imidazole-4,5-dicarboxylate and 4,4'-bipyridyl building blocks. Cryst Growth Des 2006; 6: 56471

[9] Tai XS, Jiang JH. Synthesis, crystal structure and luminescent property of $\mathrm{Cd}$ (II) complex with $N$-benzenesulphonyl- $L$ leucine. Materials 2012; 5: 1626-34. 
[10] Wang LF, Hu YX, Zhang WW, et al. Solvothermal synthesis, crystal structure and photoluminescence property of a coordination polymer based on 1,1'-ethynebenzene-3,3',5,5'-tetracarboxylate. Chin J Inorg Chem 2011; 27: 542-6.

[11] Xu GH, Ma Y, Wang K, et al. Synthesis, structure, and magnetic properties of manganese-organic frameworks of 2-methyl-4,4'biphenyldicarboxylate with different auxiliary ligands. J Mol Struct 2013; 1040: 25-32.

[12] Price DJ, Coles SJ, Hursthouse MB. Crystal structure of cobalt(II) 1,12-dodecanedioate trihydrate: a new layered coordination network. J Struct Chem 2013; 54: 474-8.

[13] Tai XS, Feng YM, Wang LT, et al. Synthesis, structure characterization and luminescent properties of ternary zinc acetate complex with 4-aminohippuric acid and1,10-phenanthroline ligand. Pol J Chem 2009; 83: 1099-104.

[14] Patra R, Goldberg I. A three-dimensional coordination polymer of 3-(3,5-dicarboxybenzyloxy)benzoic acid with zinc. Acta cryst 2013; C69: 819-21.

[15] Reger DL, Debreczeni A, Pascui AE. Heptanuclear zinc carboxylate complex: new supramolecular building unit and unique supramolecular architecture. Polyhedron 2013; 52: 1317-22.
[16] Sheldrick GM. SHELXL-97, Program for Crystal Structure Solution; University of GÖttingen: GÖttingen, Germany, 1997.

[17] Sheldrick GM. SHELXTL-97, Program for Crystal Structure Refinement; University of GÖttingen: GÖttingen, Germany, 1997.

[18] Nakamoto K. Infrared and Raman Spectra of Inorganic and Coordination Compounds, $3^{\text {rd }}$ ed. John Wiley and Sons: New York, NY, USA, vol.1, pp. 359-368, 1978

[19] Tai XS, Wei N, Wang DH. Synthesis, crystal structure and luminescent property of $\mathrm{Mg}$ (II) complex with $\mathrm{N}$ benzenesulphonyl-L-leucine and 1,10-phenanthroline. Materials 2012; 5: 558-65.

[20] Tai XS, Du LC, Zhao ZB. Synthesis, crystal structure and antibacterial activity of magnesium (II) complex with $\mathrm{N}$ benzenesulphonyl- $L$-phenylalanine and 1,10-phenanthroline. Chin J Inorg Chem 2011; 27: 575-9.

[21] Tai XS, Li YF, Zhao WH. Synthesis and crystal structure of Mg (II) complex with 3-amino-2-pyrazinecarboxylic acid ligand. J Chem Pharm Res 2014; 6: 516-20.

(C) Tai and Liu; Licensee Bentham Open.

This is an open access article licensed under the terms of the Creative Commons Attribution Non-Commercial License (http://creativecommons.org/licenses/ by-nc/3.0/) which permits unrestricted, non-commercial use, distribution and reproduction in any medium, provided the work is properly cited. 